\title{
Tenascin immunoreactivity in normal and pathological bone marrow
}

\author{
Y Soini, D Kamel, M Apaja-Sarkkinen, I Virtanen, V-P Lehto
}

\begin{abstract}
Aims: To determine the distribution of tenascin in normal and pathological bone marrow.

Methods: 48 different bone marrow lesions were studied immunohistochemically using a monoclonal antibody to tenascin.
\end{abstract}

Results: Tenascin immunoreactivity was found in lesions with increased fibrosis and high numbers of reticular fibres. The strongest immunoreactivity was found in myelofibrosis. Bone marrow from acute and chronic myeloid and lymphatic leukaemias showed weak or moderate immunoreactivity. In hyperplasias inconsistent reticular tenascin immunoreactivity was found; in normal bone marrow, only a few scattered positive fibres were occasionally seen.

Conclusions: Tenascin was generally observed in conditions in which megakaryocytic hyperplasia was a feature. This is in line with the notion that tenascin synthesis in bone marrow fibroblasts is stimulated by TGF- $\beta$ which is synthesised by the megakaryocytic lineage. Tenascin also contains EGF-like repeats. It might therefore function as a growth promoter and in this way could also stimulate synthesis of other matrix components. On the other hand, tenascin could function as an adhesive molecule to some cells of the bone marrow. The presence of tenascin in many pathological states of the bone marrow suggests that it may have a role in their pathogenesis and that it also could be a potential marker of disease.

(F Clin Pathol 1993;46:218-221)

Tenascin is an extracellular matrix protein which was originally isolated from embryonic tissues. ${ }^{1-4}$ It is also present in adult tissues in smooth muscle cells, endothelial cells, myotendineous tissue, cartilage and in healing wounds. ${ }^{5-7}$ Tenascin is synthesised by fibroblasts and glial cells. ${ }^{5}$ It is a hexameric molecule with a total molecular weight of 1900 kilodaltons. ${ }^{5}$ There are three isoforms of the molecule with molecular weights of 190 , 200 , and 230 kilodaltons and a variable tissue distribution. ${ }^{8}$ Tenascin contains epidermal growth factor-like and fibronectin-like repeats. ${ }^{9}$ Because of the epidermal growth factor-like repeats, it has been suggested that tenascin has growth promoting properties. ${ }^{10}$
Tenascin has been found in the stroma of various tumours, especially malignant ones. $^{5711-14}$ In tumour tissue it is thought to be synthesised by stromal fibroblasts that are induced by cytokines, especially TGF- $\beta .^{5}{ }^{15} 16$ Synthesis of tenascin has also been reported in embryonic bronchial epithelial cells, ${ }^{17}$ in chondroblasts, smooth muscle cells, and in some other mesenchymal cells. ${ }^{18}$ Moreover, intracytoplasmic tenascin immunoreactivity has been detected in malignant melanomas ${ }^{14}$ and in lung carcinomas. ${ }^{19}$

In haematolymphoid tissues the distribution of tenascin has been studied in lymph nodes and in spleen, ${ }^{20}{ }^{21}$ but there are no reports on the distribution of tenascin in bone marrow tissue. In splenic tissue tenascin immunoreactivity is closely associated with the reticular fibres. ${ }^{21}$ Similarly, in reactive and neoplastic lymph node tissue (except for the nodular sclerosing variant of Hodgkin's lymphoma) tenascin was seen as a reticular network, similar to that detected by the reticulin stain. ${ }^{20}$ In the nodular sclerosing variant of Hodgkin's lymphoma the entire fibrotic stromal tissue stains strongly for tenascin. ${ }^{20}$

In a previous study we introduced a novel monoclonal tenascin antibody (143DB7): this functions in formalin fixed and paraffin wax embedded material. ${ }^{1922}$ The antibody recognises all three isoforms of tenascin. ${ }^{1922}$ Using this antibody, we have now examined the distribution of tenascin in 48 bone marrow biopsy specimens to elucidate the role of tenascin in a variety of different neoplastic and reactive conditions of the bone marrow.

\section{Methods}

The material consisted of eight cases of myelofibrosis (three primary, five secondary), six chronic myeloid leukaemias, one acute myeloid leukaemia, 13 hyperplastic bone marrows (five myeloid, three megakaryocytic, two erythroid, two diffuse, one megakaryocytic and erythroid), seven normal bone marrows, four aplasias, three chronic lymphatic leukaemias, two acute lymphatic leukaemias, one hypoplastic bone marrow, one non-specific fibrosis, one atypical lymphatic infiltrate and one metastatic adenocarcinoma. The material was collected from the files of the Department of Pathology, Oulu University Hospital, between 1980-1984. The diagnosis of the cases was based on a light microscopic evaluation of the slides stained with haematoxylin and eosin, periodic acid Schiff, Gomori's reticulin stain, the Giemsa and Herovici stains. Bone marrow 
Results of immunohistochemical staining

\begin{tabular}{|c|c|c|}
\hline Diagnosis & $\begin{array}{l}\text { Number of positive } \\
\text { cases/total number of } \\
\text { cases }\end{array}$ & $\begin{array}{l}\text { Quantification of } \\
\text { immunoreactivity }\end{array}$ \\
\hline Myelofibrosis & $8 / 8$ & $\begin{array}{l}+++1+++1+++1+++ \\
+++1++1++1+\end{array}$ \\
\hline Chronic myeloid leukaemia & $4 / 6$ & $++1++1+1+1-1-$ \\
\hline Acute myeloid leukaemia & $0 / 1$ & - \\
\hline Chronic lymphatic leukaemia & $3 / 3$ & $++/+/+$ \\
\hline Acute lymphatic leukaemia & $2 / 2$ & $+1+$ \\
\hline \multicolumn{3}{|l|}{ Hyperplasia } \\
\hline Myeloid & $2 / 5$ & $+1+1-1-1-$ \\
\hline Megakaryocytic & $3 / 3$ & $+++/+/(+)$ \\
\hline Erythroid & $0 / 2$ & $-1-$ \\
\hline Erythroid and megakaryocytic & $1 / 1$ & + \\
\hline Diffuse & $2 / 2$ & $t /(+)$ \\
\hline Normal & $2 / 7$ & $(+) /(+) /-1-1-1-1-$ \\
\hline Aplasia and hypoplasia & $0 / 5$ & $-1-1-1-$ \\
\hline Fibrosis & $1 / 1$ & + \\
\hline Metastasis & $1 / 1$ & + \\
\hline Atypcal lymphoid infiltrate & $1 / 1$ & + \\
\hline
\end{tabular}

Figure 1 Case of myelofibrosis: strong reticular tenascin immunoreactivity can be seen in the bone marrow (A). In the negative control (B) (normal mouse serum) no reactivity is present (immunoperoxidase stain) by the biotinylated rabbit anti-mouse antibody and $\mathrm{ABC}$ (Dakopatts, Glostrup, Denmark). The colour was developed with diaminobenzidine, after which the sections were mounted in an aqueous medium. The sections were counterstained with a light haematoxylin stain. Negative controls consisted of substituting phosphate buffered saline $(140 \mathrm{ml} \mathrm{NaCl}$, $0.01 \mathrm{M}$ phosphate buffer, $\mathrm{pH} 7 \cdot 2$ ) and normal mouse serum for the primary antibody.

The staining reaction was evaluated quantitatively as follows: - negative; $(+)$ occasional positive fibres; + weak reactivity, ++ moderate reactivity; and +++ strong reactivity.

\section{Results}

The results are summarised in the table.

Tenascin was found in all bone marrow samples with increased fibrosis or increased amount of reticular fibres. The strongest immunoreactivity was observed in the cases with myelofibrosis; in most cases the immunoreactivity was very strong (fig 1 ), with only three cases showing moderate or weak staining. In fibrotic areas the staining was linear; in the more cellular areas it was mainly reticular. The staining pattern was similar to that obtained by reticulin staining of the same biopsy specimens. Immunoreactivity was also found in the walls of the dilated sinusoids.

Tenascin immunoreactivity could also be seen in all samples from acute and chronic lymphatic leukaemias. The reactivity was, however, weaker than in myelofibrosis. The staining pattern was reticular. Similar immunoreactivity was also seen in the positive cases of myeloid leukaemias.

Inconsistent reticular staining was seen in the hyperplastic bone marrow. Positive staining was observed in cases with myeloid or megakaryocytic hyperplasia (fig 2), while in erythroid hyperplasia there was no tenascin immunoreactivity.

In normal bone marrow staining was mostly negative. In some cases, however, a few positive fibres could be seen. In the bone trabeculae positivity could be seen in the periosteal region and in osteocytes (fig 3 ). The walls of the blood vessels also stained positive.

No tenascin could be observed in the aplastic bone marrow. In cases with fibrosis, metastatic adenocarcinoma, and atypical lymphoid infiltrate weak tenascin immunoreactivity was observed.

There was no clear correlation between the prognosis of myelofibrosis or leukaemias and tenascin immunoreactivity (data not shown). No difference was observed in tenascin immunoreactivity between the primary and secondary myelofibrosis.

\section{Discussion}

The occurrence of tenascin in bone marrow correlated with the presence of reticular fibres and fibrosis, thus displaying a pattern of expression similar to that found in lymphatic tissues and neoplasias. Normal lymph nodes and splenic tissue displayed only a faint tenas- 


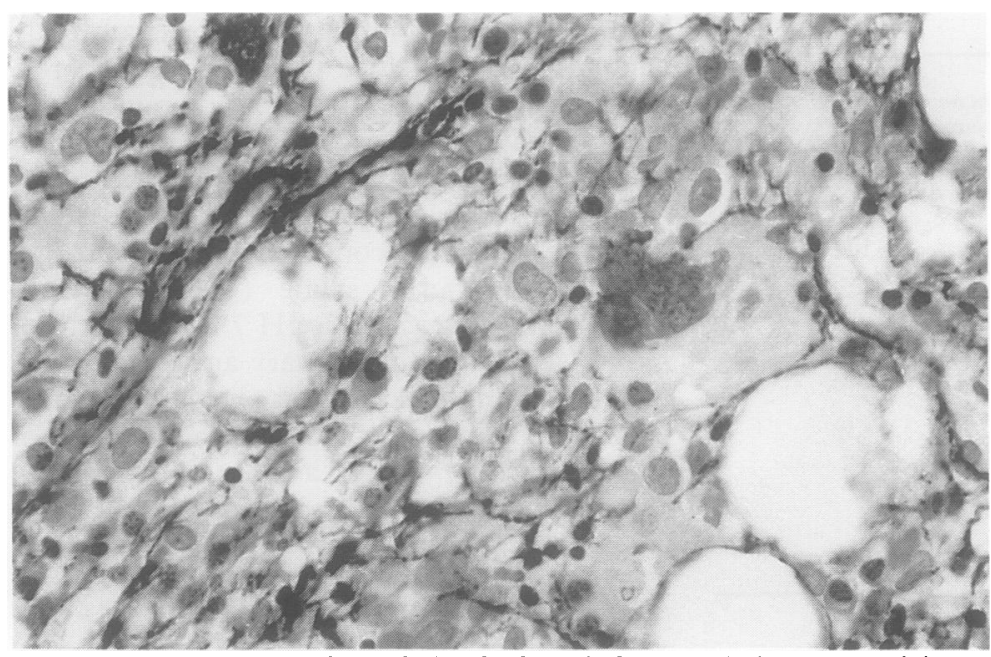

Figure 2 Megakaryocytic hyperplasia: slender reticular tenascin immunoreactivity can be seen (immunoperoxidase stain)

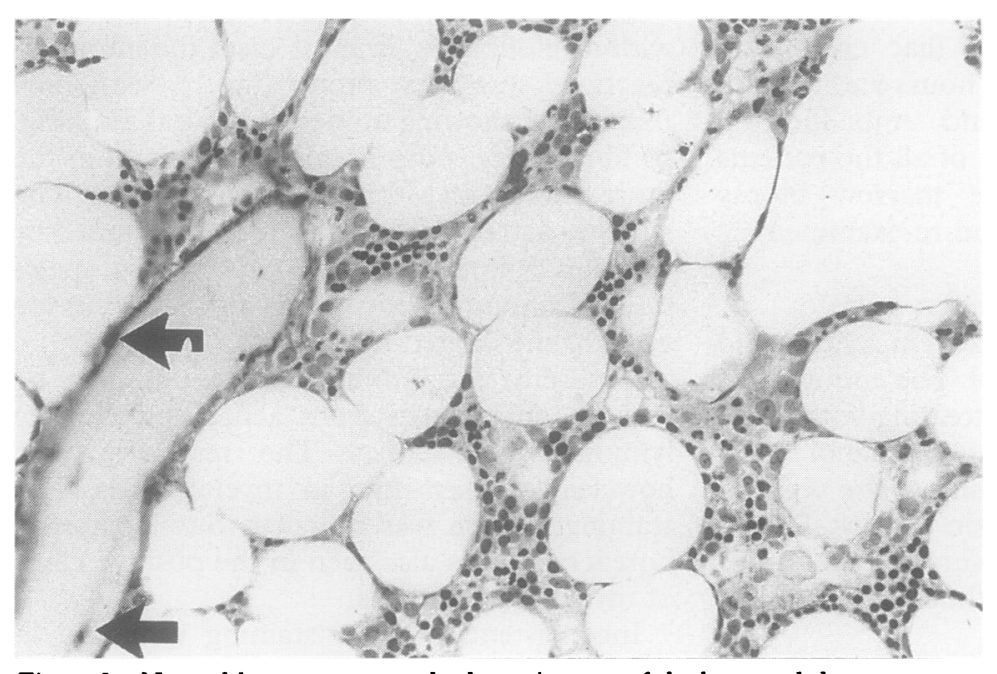

Figure 3 Normal bone marrow: only the periosteum of the bone and the osteocytes express tenascin (arrows) (immunoperoxidase stain)
In bone marrow type III procollagen immunoreactivity closely resembles that of reticulin staining. ${ }^{25}$ In myelofibrosis, the fibrous tissue also strongly stains for type III procollagen while laminin and type IV immunoreactivity can only be seen in the walls of the blood vessels and sinusoidal structures. ${ }^{25}$ As tenascin follows the reticular staining pattern, its distribution is similar to that of type III procollagen. There are, however, no reports of any association between these two molecules. On the other hand, it is known that tenascin may be attached to fibronectin. ${ }^{8}$ Interestingly, there is also a pronounced stromal deposition of fibronectin in myelofibrosis. ${ }^{26}$

The variability in tenascin immunoreactivity between different disease states of the bone marrow points to the fact that tenascin might have a role in their pathogenesis. It is known that tenascin contains EGF-like repeats. ${ }^{9}$ As pointed out earlier, EGF have been implicated in the pathogenesis of bone marrow fibrosis. ${ }^{24}$ Tenascin could therefore stimulate the fibrogenesis in bone marrow. Moreover, tenascin, via its EGF-like properties, might function as a growth promoting substance. In fact, it has been shown that EGF, along with several other growth stimulating substances, is capable of stimulating the proliferation of fibroblastic colony forming units in the bone marrow. ${ }^{28}$ On the other hand, tenascin may function as an adhesive molecule to the cells of the bone marrow.

In normal bone marrow occasional tenascin positive fibres could be found, indicating that low amounts of tenascin are present in the reticular backbone of the marrow. In the bone tissue tenascin was seen in obsteocytes and in the periosteum. Similar immunoreactivity in bone tissue has been reported earlier ${ }^{7}$ and this also served as an internal positive control for the staining. No positivity was found in aplastic bone marrows which suggests that the matrix framework of the bone marrow is lost in aplasia.

In summary, the occurrence of tenascin in various pathological conditions of the bone marrow makes it a putative marker of disease. It could also be used as an adjunct in the diagnosis and follow up of myelofibrosis, as has been suggested for some other extracellular matrix proteins, such as laminin and type IV collagen. Derived protein fragments of these have been found in patients' serum. ${ }^{26}$ To date, however, there are no serum markers for tenascin.

This study was supported by the Finnish Anti-Tuberculosis Association, the Finnish Medical Research Council, the Finnish Cancer Research Fund, and the Sigrid Juselius Foundation. of the megakaryocytic lineage. ${ }^{242627}$ Tenascin synthesis in fibroblasts is induced by TGF$\beta .^{51516}$ The fact that tenascin immunoreactivity is mostly associated with conditions in which megakaryocytic hyperplasia features is well in line with this observation. However, neoplastic myeloid and hyperplastic states also show tenascin immunoreactivity, though to a lesser degree. This may be partly explained by the fact that bone marrow stem cells are also capable of synthesising TGF- $\beta$. $^{27}$
1 Bourdon MA, Wikstrand CJ, Furthmayr H, Matthews TJ, Bigner DD. Human glioma-mesenchymal extracellular matrix antigen defined by monoclonal antibody. Cancer Res 1983;43:2796-805.

2 Chiquet M, Fambrough DM. Chick myotendineous antigen. I.A. Monoclonal antibody as a marker for tendon and muscle morphogenesis. If Cell Biol 1984;98: 1937-46.

3 Crossin KL, Hoffman S, Grumet M, Thiery J-P, Edelman GM. Site-restricted expression of cytotactin during development of the chicken embryo. F Cell Biol 1986; 102:1917-30.

4 Chuong C-M, Crossin KL, Edelman GM. Sequential 
expression and differentiation function of multiple adhesion molecules during the formation of cerebellar cortical layers. F Cell Biol 1987;104:331-42.

5 Erickson HP, Bourdon MA. Tenascin: an extracellular matrix protein prominent in specialized embryonic tissues and tumours. Ann Rev Cell Biol 1989;5:71-92.

6 Chuong C-M, Chen H-M. Enhanced expression of neural cell adhesion molecules and tenascin (cytotactin) during wound healing. Am f Pathol 1991;138:427-40.

7 Natali PG, Nicotra MR, Borri C, Castellani P, Risson AM, Zardi $\mathrm{L}$. Comparative analysis of the expression of the extracellular matrix protein tenascin in normal human foetal, adult and tumour tissues. Int $\mathcal{F}$ Cancer 1991 47:811-16.

8 Chiquet-Ehrismann R, Matsuoko Y, Hofer U, Spring J Bernasconi $C$, Chiquet $M$. Tenascin variants: differential binding to fibronectin and distinct distribution in cell cultures and tissues. Cell Regulation 1991;2:927-38.

9 Jones FS, Burgoon MP, Hoffman S, Crossin KL, Cunningham BA, Edelman GM. A cDNA clone for cytotactin contains sequences similar to epidermal growth factorlike repeats and segments of fibronectin and fibrinogen. Proc Natl Acad Sci USA 1988;85:2186-90.

10 Engel J. EGF-like domains in extracellular matrix proteins: Engel J. EGF-like domains in extracellular matrix proteins:
localized signals for growth and differentiation? FEBS Letts 1989;251:1-7.

11 Erickson HP, Lightner VA. Hexabrachion protein (tenascin, cytotactin, brachionectin) in connective tissue, embryonic brain and tumours. Adv Cell Biol 1988;2:55-90.

12 Howeedy AA, Virtanen I, Laitinen L, Gould NS, Koukoulis GK, GouldVE. Differential distribution of tenascin in the normal, hyperplastic and neoplastic breast. Lab Inves 1991;63:798-806.

13 Vollmer G, Siegal GP, Chiquet-Ehrismann R, Lightner VA, Arnholdt $H$, Knuppen $R$. Tenascin expression in the human endometrium and in endometrial adenocarcinomas. Lab Invest 1990;2:725-30.

14 Natali PG, Nicotra MR, Bartolazzi A, et al. Expression and production of tenascin in benign and malignant lesions of production of tenascin in benign and malignant lesions
melanocytic lineage. Int $\mathcal{F}$ Cancer 1990;46:586-90.

15 Pearson CA, Pearson D, Shibahara S, Hofsteenge J, Chiquet Ehrismann R. Tenascin: cDNA cloning and induction by TGF-beta. EMBO $\mathcal{f} 1988 ; 7: 2977-81$.

16 Chiquet-Ehrismann $R$. What distinguishes tenascin from fibronectin? FASEB f 1990;4:2598-604.
17 Koch M, Wehrle-Haller B, Baumgartner S, Spring J, Brubacher D, Chiquet M. Epithelial synthesis of tenascin at tips of growing bronchi and graded accumulation in basement membrane and mesenchyme. Exp Cell Res 1991;194:297-300.

18 Prieto AL, Jones FS, Cunningham BA, Crossin KL, Edelman GM. Localization during development of alternatively spliced forms of cytotactin mRNA by in situ hybridization. $f$ Cell Biol 1990;111:685-98.

19 Soini Y, Pääkkö P, Nuorva K, et al. Tenascin immunoreactivity in lung tumours. Am $\mathcal{f}$ Clin Pathol (in press).

20 Soini Y, Alavaikko $M$, Lehto V-P, Virtanen I. Tenascin in reactive lymph nodes and in malignant lymphomas. Path Res Pract (in press)

21 Liakka A, Autio-Harmainen H. Distribution of the extracellular matrix proteins tenascin, fibronectin, and vitronectin in fetal, infant, and adult human spleens. $f$ Histochem Cytochem 1992;40:1203-10.

22 Soini Y, Pääkkö P, Virtanen I, Lehto Veli-Pekka. Tenascin in salivary gland tumours. Vichows Arch (Pathol Anat) 1992;421:217-22.

23 Hsu S-M, Raine L, Fanger $H$. Use of avidin-biotinperoxidase complex $(\mathrm{ABC})$ in immunoperoxidase techniques: A comparison between $\mathrm{ABC}$ and unlabelled antibody (PAP) procedures. $\mathcal{F}$ Histochem Cytochem 1981; 29:577-80.

24 Kimura A, Katoh O, Hyodo H, Kuramoto A. Transforming growth factor-beta regulates growth as well as collagen and fibronectin synthesis of human marrow fibroblasts. Br $\mathcal{F}$ Haematol 1989;72:486-91.

25 Apaja-Sarkkinen M, Autio-Harmainen H, Alavaikko M Risteli J, Risteli L: Immunohistochemical study of basement membrane proteins and type III procollagen in myelofibrosis. $B r \mathcal{F}$ Haematol 1986;63:571-80.

26 Reilly JT. Pathogenesis of idiopathic myelofibrosis: role of growth factors. 7 Clin Pathol 1992;45:461-4.

27 Ellingsworth LR, Brennan JE, Fok K, et al. Antibodies to the N-terminal portion of cartilage-inducing factor $A$ and the $\mathrm{N}$-terminal portion of cartilage-inducing factor $\mathrm{A}$ and transforming growth factor beta. Immunohistochemical localization and association with

28 Wang QR, Yan ZJ, Wolf NS. Dissecting the haematopoietic microenvironment. VI. The effects of several growth factors on the in vitro growth of murine bone marrow CFU-F. Exp Haematol 1990;18:341-7. 